\title{
DIRETOS E DEVERES DO CONSUMIDOR NO CONTRATO DE SEGURO DE AUTOMÓVEL
}

\section{ARTIGO ORIGINAL}

COSTA, Andressa Cristina Barretto da ${ }^{1}$

COSTA, Andressa Cristina Barretto da. Diretos e deveres do consumidor no contrato de seguro de automóvel. Revista Científica Multidisciplinar Núcleo do Conhecimento. Ano. 07, Ed. 01, Vol. 01, pp. 148-163. Janeiro de 2022. ISSN: 24480959, Link de acesso: https://www.nucleodoconhecimento.com.br/lei/contrato-deseguro, DOI: 10.32749/nucleodoconhecimento.com.br/lei/contrato-de-seguro

\section{RESUMO}

Quando o assunto é contrato de seguro, o seguro de automóvel é uma das modalidades mais comuns. É normal, nos dias de hoje, que as pessoas contratem um seguro para proteger seus veículos de eventuais infortúnios, vez que automóveis são rotineiramente expostos a riscos. Apesar de sua grande adesão, este tipo de contrato possui certas especificidades que podem gerar muitas dúvidas por parte de quem o contrata. Assim, antes de realizar a contratação é importante que o proponente tenha em mente o que está contratando. Neste contexto, o presente artigo, tem como questão norteadora: quais são os direitos e deveres do segurado e da seguradora em um contrato de seguro? Para respondê-la, utilizou como metodologia a pesquisa documental com o objetivo de fornecer informações sobre o contrato de seguro de automóvel, além de esclarecer os direitos e deveres do segurado e da empresa seguradora decorrentes da efetivação do seguro. Concluindo-se que o contrato gera obrigações para ambas as partes, sendo que a principal obrigação do segurado é pagar o prêmio contratado, já a da Seguradora é prestar o serviço determinado no contrato quando solicitado. Além disso, para

\footnotetext{
${ }^{1}$ Graduada em Direito pela Universidade Cândido Mendes, pós-graduada em Advocacia Tributária pela Universidade Cândido Mendes e pós-graduada em Direito Militar pela faculdade Signorelli. ORCID: 0000-00023867-4452.
}

RC: 104723

Disponível em: https://www.nucleodoconhecimento.com.br/lei/contrato-de-seguro 
manter o equilíbrio da relação, os contraentes devem agir com clareza, boa-fé e honestidade, prestando sempre informações e declarações de acordo com a verdade.

Palavras-chave: contrato, seguro, apólice, deveres, obrigações.

\section{INTRODUÇÃO}

Devido ao desenvolvimento da economia, ao aumento das relações negociais e a necessidade de proteção do patrimônio, a contratação de seguro é prática cada vez mais comum em nossa sociedade. No entanto, o contrato de seguro possui especificidades que geram muitas dúvidas e problemas na relação entre segurado e Seguradora. Como, por exemplo, questões sobre como se deve agir perante a Seguradora, em quais hipóteses pode-se acionar o seguro, quais os direitos do segurado.

Este estudo apresentará informações gerais sobre o contrato de seguro, mas o principal foco é o seguro de automóvel.

O contrato de seguro é considerado bilateral, pois gera obrigações para ambos os contratantes. A Seguradora se compromete a pagar indenização ou prestar o serviço contratado na apólice e o segurado possui obrigações de efetuar o pagamento do prêmio pactuado, de prestar informações verdadeiras, de agir de boa-fé etc.

O seguro de automóvel pode fornecer diversos tipos de serviços, tais como indenização em caso de sinistro; guincho; chaveiro; disponibilização de veículo reserva; entre outros. Cabe ao segurado definir as coberturas que atendam aos seus interesses e contratá-las junto à Seguradora.

O Código Civil de 2002 traz no capítulo XV disposições específicas sobre o contrato de seguro (artigos 757 a 802). Contudo, tal contrato também é regulado pelo Código de Defesa do Consumidor o qual, em seu artigo $3^{\circ}$, $\S 2^{\circ}$, estabelece que serviço é qualquer atividade fornecida no mercado de consumo, mediante remuneração, inclusive as de natureza securitária.

RC: 104723

Disponível em: https://www.nucleodoconhecimento.com.br/lei/contrato-de-seguro 
Neste contexto, o presente artigo, tem como questão norteadora: quais são os direitos e deveres do segurado e da seguradora em um contrato de seguro? $\mathrm{O}$ presente trabalho foi elaborado com o escopo de informar as principais características do contrato de seguro de automóvel, bem como esclarecer os direitos e deveres do segurado.

O método de coleta dos dados para prestar as informações do presente estudo foi pesquisa documental, sendo analisados leis, artigos, trabalhos e documentos pertinentes ao tema.

O artigo será iniciado com esclarecimentos básicos sobre o contrato de seguro, depois prestará informações sobre aceitação da proposta e características deste tipo de contrato, pois informações gerais são necessárias para o entendimento dos deveres e obrigações inerentes ao contrato. Após, abordará a questão principal, que norteou a elaboração do presente, que são os direitos e deveres do segurado e da Seguradora no contrato de seguro.

\section{DO SEGURO DE AUTOMÓVEL}

Antes de adentrar ao assunto dos direitos e deveres do segurado no contrato de seguro, é pertinente entender primeiro o que é o contrato de seguro de automóvel, quais bens podem ser segurados por este tipo de contrato, quais as coberturas existentes, o que é prêmio, quais são os limites das indenizações, entre outras considerações que serão abordadas neste tópico.

Contrato de seguro é aquele pelo qual uma das partes, a Seguradora, se obriga perante o segurado, por meio de pagamento de um prêmio, a indenizá-lo do prejuízo econômico resultante de riscos futuros, possíveis, incertos, lícitos e independentes da vontade das partes. Ressalta-se que prêmio é o valor pago pelo segurado para a contratação do seguro, muitos confundem este termo achando que prêmio é a indenização que o Segurador deve pagar. Mas, não o é, prêmio é o preço pago pelo segurado para ter seu bem segurado. Conforme informação da SUSEP Superintendência De Seguros Privados (s.d) - "O que é prêmio do seguro? É o valor 
que o segurado paga à seguradora pelo seguro para transferir a ela o risco previsto nas Condições Contratuais. Pagar o prêmio é uma das principais obrigações do segurado."

O contrato de seguro é regulado no título XV do Código Civil vigente nos artigos 757 a 802. Contudo, por tratar-se de relação de consumo, a esses contratos também serão aplicadas as disposições do Código de Defesa do Consumidor. Inclusive, o Código de Defesa do Consumidor (1990), em seu artigo 3요 § 2[2] expressamente incluiu a atividade securitária no rol das abrangidas pelo Código. É, portanto, regido por ambos os Códigos, nas palavras de José Sebastião (2012):

Assim, conclui-se que a relação jurídica firmada entre seguradora e segurado é uma relação jurídica de consumo. Não olvidando, entretanto, o fato de que esta afirmação não tem por consequência, a exclusão da incidência de outras normas. Este fato, portanto, cria a possibilidade de incidência cumulativa do Código de Defesa do Consumidor com outras normas aos contratos de seguro.

Sendo certo que será aplicado o Código de Defesa do Consumidor, em eventuais litígios, toda vez que a Seguradora puder ser caracterizada como fornecedora e o segurado como consumidor final.

Todos os veículos terrestres de propulsão a motor e seus reboques, desde que não andem sobre trilhos, podem ser objeto de seguro nesta modalidade. Assim, são seguráveis: moto, carro, ônibus, cavalo mecânico, carroceria, semirreboques e todos os correlatos.

Cabe mencionar que equipamentos como escavadeiras e carregadeiras utilizadas em grandes obras, tratores, colheitadeiras e outros tipos de implementos agrícolas, apesar de serem automotores e terrestres, não podem ser objetos de seguro na modalidade automóvel, vez que para tais máquinas existe um seguro específico que é o seguro de Equipamentos.

Em um seguro de automóvel, as coberturas oferecidas têm como objetivo atender às necessidades dos segurados diante da possibilidade de existência de prejuízos em razão de danos causados acidentalmente pelo uso de seus veículos ou resultante de 
ação de terceiros. São fornecidas as seguintes coberturas: colisão, furto, roubo e incêndio, podendo a perda do bem ser parcial (caso em que a Seguradora autorizará os reparos) ou total (Seguradora providenciará o pagamento da indenização integral do bem).

A cobertura do seguro de automóvel pode, ainda, ser conjugada com cobertura de responsabilidade civil facultativa de veículos (RCF-V) e de acidentes pessoais para passageiros (APP). A cobertura de RCF-V pode ser dividida em duas modalidades: a que cobre danos materiais causados a terceiros (DM) e a de danos corporais causados a terceiros (DC). A cobertura de APP, por sua vez, pode ser dividida em morte, invalidez e despesas médicas e hospitalares.

Há também a possibilidade de a apólice de automóvel ser contratada com cobertura para danos morais que compreende o pagamento de possíveis indenizações oriundas de processo por danos morais movidos em decorrência de sinistros cobertos pela apólice de seguro, Elaina (2019) informa que "a cobertura para danos morais entra em ação quando existem indenizações que devem ser pagas pelo segurado, seja por calúnias, danos estéticos ou morais". Muitas vezes, a cobertura para danos morais no seguro auto se encontra inserida na cobertura para terceiros, ou RCF-V, mas isto não é uma regra e dependendo da Seguradora esta cobertura deverá ser contratada separadamente.

Além disso, pode o segurado contratar coberturas adicionais, como, por exemplo: acessórios, rádios, ar-condicionado, antenas, guindastes, frigoríficos (caminhões frigoríficos), diárias de paralisação, etc. Outros opcionais do seguro auto são: assistência de mecânico, reboque, chaveiro, troca de vidros; e disponibilização de veículo reserva em caso de sinistro.

Enfim, são inúmeras as coberturas que podem ser contratadas em um seguro de automóvel, que podem variar a depender da região e da Seguradora, devendo o segurado em cada caso verificar a sua necessidade e contratar as coberturas que melhor lhe atendem. 
Vale ressaltar que o valor da importância segurada pactuado na apólice para cada cobertura representará o limite máximo de responsabilidade assumido pela Seguradora. Todo e qualquer prejuízo que ultrapassar o limite do valor contratado pelo segurado será de sua própria responsabilidade. Conforme dispõe a Agência Reguladora de Seguros Privados (SUSEP, 2006):

O que é limite máximo de indenização? Também chamado de importância segurada, o limite máximo de indenização representa, para cada uma das coberturas contratadas pelo segurado, o valor máximo que esse poderá receber em caso de um sinistro amparado pela respectiva cobertura. $O$ segurado deverá estar atento, em cada cobertura, ao valor estipulado para o limite máximo de indenização, pois, dependendo da forma de contratação do seguro, isso poderá acarretar o recebimento parcial dos prejuízos.

\section{CARACTERÍSTICAS DO CONTRATO DE SEGURO}

Para compreender as obrigações e direitos provenientes do contrato de seguro, é importante ter conhecimento das características deste tipo de contrato, por isso, neste tópico faremos breves considerações sobre as características do contrato de seguro.

Primeiramente, informamos que contrato é toda espécie de negócio jurídico o qual gera obrigações entre as partes. Segundo a maioria da doutrina, o contrato de seguro é nominado, bilateral, oneroso, comutativo, consensual e de adesão.

Nominado é aquele expressamente descrito pelo legislador, em que a lei, além de regulá-los, atribui padrões específicos.

Bilateral é uma característica relacionada à reciprocidade de obrigações, de forma que cada uma das partes fica subordinada a uma determinada prestação. Assim, cada contratante é credor e devedor ao mesmo tempo. Biseli (2015), citando Washington de Barros, aduz

...é da essência desses contratos a reciprocidade das prestações; o compromisso assumido por uma das partes encontra sua exata correspondência no compromisso dá outros; esses compromissos são correlativos e intimamente ligados entre si; cada um dos contratantes se

RC: 104723

Disponível em: https://www.nucleodoconhecimento.com.br/lei/contrato-de-seguro 
obriga a executar, porque outro tanto lhe promete o segundo contratante; o sacrifício de um é contrabalanceado pela vantagem advinda do outro.

No contrato oneroso as partes reciprocamente transferem alguns direitos. Em decorrência das obrigações estabelecidas nos contratos de seguro, eles são, incontroversamente, identificados como onerosos, já que compete ao segurado pagar o prêmio para obter a garantia prestada pelo segurador. Mendes (2014) alega que:

É um contrato oneroso porque implica em pagamentos pelas partes. Neste tipo de contrato, o Segurado transfere o risco mediante o pagamento de um custo (prêmio de seguro) à Companhia de Seguros, que por sua vez, caberá fazer a indenização na possibilidade da ocorrência de riscos previstos e cobertos pela apólice contratada.

É consensual porque é fundamentado pela vontade das partes, devendo ser respeitada a obrigatoriedade da forma escrita prevista no artigo 759 do Código Civil de 2002[3].

Considera-se o contrato de seguro como de adesão, já que na contratação o segurado deve aderir as condições e cláusulas impostas pela Seguradora, não havendo margem para discordância ou discussão. Alessandra Hendler (2006) aduz que:

Com base neste artigo, Difini (2005) classifica o contrato securitário como de adesão, pois é um contrato de homogeneização de riscos com o cálculo atualizado, o que exige instrumento contratual ágil e fácil, como o é o de adesão. No entanto, atenta para possibilidade de existência de cláusulas abusivas delimitadas no art. 51 do CDC, uma vez que esta espécie de contrato elimina qualquer tipo de negociação entre as partes, visto que as cláusulas se apresentam praticamente prontas ao segurado.

Isto ocorre em razão da necessidade de uniformizar as cláusulas e condições para todos os Segurados, tendo em vista que serão analisados os detalhes do risco para definição da taxa do seguro e limitação dos riscos que serão cobertos.

Por fim, há divergência na doutrina na definição deste tipo de contrato como comutativo ou aleatório. Para Rocha (2014) é aleatório: 
Aleatório: É um contrato aleatório porque não há equivalência entre as prestações de serviços. A Companhia de Seguros assume o compromisso e obrigação de indenizar seu cliente, o Segurado, por um risco que pode ou não ocorrer. Neste tipo de contrato, o Segurador pode obter lucro ou prejuízo, dependendo exclusivamente da ocorrência de eventos futuros e incertos. A aleatoriedade é uma característica relevante dos contratos de seguro, considerando a sua própria função econômica.

Já Bisseli (2015) argumenta que o contrato de seguro possui natureza comutativa:

A comutação no contrato de seguro se dá, portanto, entre o prêmio pago pelo segurado e a garantia prestada pelo segurador. Isso porque, ao receber a garantia de seu interesse segurável, o segurado obtém uma vantagem, a qual jamais receberia fosse o contrato de seguro inexistente.

"Ao obter garantia do interesse para a hipótese de realização do risco predeterminado (sinistro), o segurado obtém uma vantagem ou atribuição patrimonial sem a qual permaneceria em estado potencial de dano".

Destarte, entendemos que os contratos de seguro são comutativos, uma vez que no momento da celebração da avença as partes estabelecem as obrigações rigorosamente. Com o advento do atual Código Civil, não há como se negar que, no contrato de seguro, a prestação está, por força de lei, avençada: enquanto ao segurado tem a obrigação deve pagar o prêmio, o segurador se obriga a garantir o legítimo interesse daquele.

\section{ACEITAÇÃO DA PROPOSTA}

Outro ponto relevante para entender o contrato de seguro e os direitos e obrigações dele provenientes é a formulação e aceitação da proposta, pois este documento representa o início da relação jurídica entre as partes.

Qualquer pessoa pode demonstrar junto a uma Seguradora o interesse em ter seu veículo segurado. Então, a Seguradora fará a cotação da proteção, avisando se está disposta a assumir o risco de proteger o veículo ou não.

A seguradora tem o prazo de 15 dias para se pronunciar quanto à proposta de seguro apresentada pelo segurado ou seu corretor, contados a partir da data indicada na proposta de seguro, ou, na falta desta, da data do recebimento da proposta pela Seguradora. Conforme publicação dos Oficiais de Justiça do estado de São Paulo (2011):

RC: 104723

Disponível em: https://www.nucleodoconhecimento.com.br/lei/contrato-de-seguro 
O prazo para aceitação do seguro será especificado na proposta, não podendo ser superior a 15 dias, contados da data do seu recebimento. Havendo recusa, o valor pago deverá ser devolvido com atualização até a efetiva restituição, através de índice previamente determinado.

O Procon-SP alerta para, em caso do contrato assinado fora do estabelecimento comercial, o consumidor tem direito de arrependimento no prazo de sete dias, previsto no artigo 49 do Código de Defesa do Consumidor.

Será considerada como início da cobertura de risco a data indicada na proposta de seguro. Na falta desta, valerá a data do recebimento da proposta pela seguradora. Por isso, é importante que você exija o preenchimento correto do dia de assinatura do contrato.

Encerrado esse prazo, não ocorrendo a recusa da seguradora, o seguro passa a ser considerado aceito.

Caso o risco não seja aceito pela Seguradora, esta deverá comunicar formalmente a não aceitação do seguro ao proponente, justificando o motivo que ensejou a sua recusa. Além disso, o valor pago pelo proponente deverá ser devolvido com atualização até a efetiva restituição, através de índice previamente determinado.

Havendo aceitação da proposta, ocorrerá a emissão da apólice de seguro, documento que caracteriza o negócio jurídico do seguro, a qual deverá mencionar os riscos assumidos, o início e o fim de sua validade, o limite da garantia e o prêmio devido, e, quando for o caso, o nome do segurado e o do beneficiário, conforme inteligência do artigo 760 do CC (2002)

A apólice ou o bilhete de seguro serão nominativos, à ordem ou ao portador, e mencionarão os riscos assumidos, o início e o fim de sua validade, o limite da garantia e o prêmio devido, e, quando for o caso, o nome do segurado e o do beneficiário.

\section{DIREITOS DO SEGURADOE OBRIGAÇÕES DA SEGURADORA}

O contrato de seguro de automóvel é bilateral, pois existe uma reciprocidade no que se refere ao cumprimento das obrigações. Nesse sentido, ambas as partes (segurado e o segurador) têm direitos e deveres a cumprir. A falta de cumprimento 
de obrigação contratual por uma das partes pode desobrigar a outra também de cumprir o preestabelecido em contrato.

Segundo o artigo 757 do CC de 2002, "Pelo contrato de seguro, o segurador se obriga, mediante o pagamento do prêmio, a garantir interesse legítimo do segurado, relativo a pessoa ou a coisa, contra riscos predeterminados." Deste artigo, retiramos a principal obrigação da Seguradora para com o segurado que é o oferecimento da assistência contratada.

É direito do consumidor usufruir de toda a assistência contratada na apólice do seguro. Portanto, de acordo com as condições previamente estabelecidas, a Seguradora tem a obrigação de oferecer os serviços pactuados no contrato.

Mas, como saber as coberturas contratadas? Uma apólice tem muitos pontos específicos, sendo assim, é dever da Seguradora esclarecer todas as particularidades e elementos do contrato. Todas as informações sobre o seguro devem ser apresentadas de forma clara e detalhada em seu contrato: data de vigência, coberturas, valores para pagamento, data de validade, condições do seguro, cláusulas contratadas, riscos excluídos e outros. Os procedimentos para a liquidação de sinistros, inclusive a forma como é calculada a indenização, também devem ser claramente informados na apólice, com especificação dos documentos básicos necessários a serem apresentados para cada tipo de cobertura.

Assim, registramos outro direito do segurado que é o de receber as informações do contrato de forma direta e com clareza. Segundo site da corretora Da Veiga e Higuchi (2021):

O contrato de seguro é caracterizado por suas inúmeras particularidades e detalhes específicos. É por isso que a leitura e assinatura desse acordo devem ser realizadas com cautela e bastante atenção. Até porque as cláusulas consideradas complexas e pouco claras, que se apresentem de difícil entendimento, serão interpretadas a favor do consumidor.

A recomendação é somente assinar o documento caso esteja totalmente ciente de todas as cláusulas estipuladas no contrato. Se o segurado possuir alguma dúvida, a 
seguradora tem o dever de esclarecer os questionamentos e fornecer todas as informações corretas, com clareza e transparência.

Outro direito do segurado é o de ser comunicado previamente das alterações contratuais, pois qualquer mudança realizada no documento sem um comunicado prévio, pode ser configurada como ação arbitrária. A corretora Da Veiga e Higuchi (2021) esclarece que

As mudanças realizadas no contrato devem ser confirmadas por ambas as partes, ou seja, de comum acordo. Nenhuma alteração pode ser feita de modo unilateral ou arbitrário, mesmo que traga benefícios para a parte contrária, sob pena de se tornar inválida.

Então, antes de realizar uma alteração contratual, é necessário que a empresa informe ao segurado, independentemente, se a alteração trouxer benefícios ao segurado ou não.

A necessidade de comunicação é para qualquer alteração contratual, inclusive nos casos de cancelamento da apólice por inadimplemento do segurado. Tal é a importância da comunicação que há entendimento sumulado do Supremo Tribunal de Justiça o qual determina que a Seguradora deverá indenizar o segurado ainda que este esteja inadimplente, se este não estiver sido comunicado do atraso no pagamento. Conforme súmula 616 do STJ (2018): "A indenização securitária é devida quando ausente a comunicação prévia do segurado acerca do atraso no pagamento do prêmio, por constituir requisito essencial para a suspensão ou resolução do contrato de seguro."

Em caso de sinistro, ocorrência de todo evento que tem cobertura no seguro contratado e esteja especificado na apólice, não basta que a Seguradora preste a assistência contratada, ela deverá fazê-lo dentro do prazo de liquidação determinado no próprio contrato que segundo a Superintendência de Seguros Privados (SUSEP) não deverá ultrapassar trinta dias, contados a partir do cumprimento de todas as exigências contratuais feitas ao segurado. Luiza (2020) em seu trabalho explica que: 
Um sinistro, quando coberto no contrato, vai gerar uma indenização paga pela seguradora. Essa indenização será do tipo parcial ou integral.

A indenização parcial do seguro auto é paga quando os danos ocorridos ao veículo correspondem a, no máximo, $75 \%$ do valor de mercado do carro. Então, o veículo será consertado.

Geralmente, isso requer o pagamento da franquia do seguro auto pelo consumidor.

Já a indenização integral não exige franquia, e é paga quando os danos ao carro são superiores a $75 \%$ do seu valor de mercado.

Independentemente do tipo de sinistro, parcial ou integral, a seguradora tem até 30 dias para liquidá-lo, ou seja, para pagar a indenização.

A contagem do prazo poderá ser suspensa quando, no caso de dúvida fundada e justificável, forem solicitados novos documentos, sendo reiniciada a contagem a partir do cumprimento das exigências pelo segurado, conforme determinação da SUSEP (2006).

A liquidação dos sinistros deverá ser feita num prazo não superior a 30 dias, contados a partir do cumprimento de todas as exigências contratuais feitas ao segurado.

Os procedimentos para a liquidação de sinistros devem ser claramente informados na apólice, com especificação dos documentos básicos necessários a serem apresentados para cada tipo de cobertura.

A contagem do prazo poderá ser suspensa quando, no caso de dúvida fundada e justificável, forem solicitados novos documentos, sendo reiniciada a partir do cumprimento das exigências pelo segurado.

Se a Seguradora não liquidar o sinistro dentro do prazo determinado, cabe ao segurado o direito de receber o valor com atualização monetária, sem prejuízo do recebimento de juros moratórios, conforme preleciona o artigo 772 do Código Civil (2002): "A mora do segurador em pagar o sinistro obriga à atualização monetária da indenização devida segundo índices oficiais regularmente estabelecidos, sem prejuízo dos juros moratórios."

Consideram-se também obrigações da Seguradora, segundo Biselli (2015): 
(i) a constituição de reservas e provisões, preservando sua higidez econômico-financeira a permitir fazer frente às indenizações devidas;

(ii) eventualmente, contratar cosseguro e/ou resseguro, a depender do caso concreto; (iii) pagar ao segurado as despesas de salvamento (artigos 771 e 779, ambos do Código Civil) e (iv) promover a regulação dos sinistros.

\section{OBRIGAÇÕES DO SEGURADOE DIREITOS DA SEGURADORA}

São obrigações básicas do segurado realizar com regularidade a manutenção do seu veículo e mantê-lo em condições de trafegabilidade com segurança. O segurado deve sempre trafegar com seu veículo em boas condições, assim, deve sempre: verificar os freios e as luzes externas do veículo; trafegar com todos os itens de segurança exigidos pela lei, tais como triângulo; respeitar o número máximo de passageiros permitidos para o seu veículo; transportar bagagens e cargas adequadamente (em lugares apropriados para seu transporte e respeitando a limitação de peso e altura do veículo), evitando queda e deslizamento de carga; entre outras medidas.

Em relação ao contrato de seguro, a primeira obrigação que trataremos nesse estudo é a de manter-se adimplente com as parcelas do prêmio. Caso o segurado não honre o acordo e deixe de proceder ao pagamento das prestações da apólice, ficando inadimplente, ele deverá pagar juros e poderá perder o direito à indenização, se o contrato não estabelecer previsão em contrário. Gabriel Dau (2020) alega que:

Manter os pagamentos em dia - Para uma manutenção satisfatória do serviço contratado, esse ponto é imprescindível. Se o segurado não manter as mensalidades em dia, pode perder o direito à cobertura. Se estiver com problemas financeiros, o ideal é entrar em contato com a corretora de seguros e fazer uma negociação.

Outra obrigação importante é a de agir em conformidade com os princípios de probidade e boa-fé, os quais envolvem honestidade e lealdade. Tais práticas devem ser adotadas em todo tipo de contrato, tanto na fase pré-contratual (emissão da proposta de seguro) quanto na etapa contratual (contrato efetivado, emissão da apólice). Segundo disposição da corretora Da Veiga e Higuchi (2021): 
Os princípios de boa-fé objetiva envolvem honestidade e lealdade. Trata-se de um comportamento fundamental para que haja a manutenção do equilíbrio contratual. Nesse sentido, o segurado deve ser verdadeiro e responsável com relação às suas atitudes, sob pena de liberar o segurador das obrigações contratuais, em caso de comprovada má-fé.

Para o contrato de seguro, o Código Civil de 2002 expressamente determinou que os contratantes devem agir de acordo com a boa-fé, conforme inteligência artigo 765 "O segurado e o segurador são obrigados a guardar na conclusão e na execução do contrato, a mais estrita boa-fé e veracidade, tanto a respeito do objeto como das circunstâncias e declarações a ele concernentes."

As informações do perfil do segurado, do perfil do condutor principal, do endereço de pernoite do veículo, tipo de garagem e todas aquelas circunstâncias que podem majorar o risco de ocorrência de um sinistro interferem no valor do prêmio a ser calculado pela Seguradora, vez que este cálculo é elaborado levando em consideração a análise da probabilidade de ocorrência de certo evento danoso.

Por isso, no contrato de seguro de automóvel é essencial que o segurado forneça informações reais e verdadeiras para haver um equilíbrio contratual e que a Cia Seguradora possa calcular um prêmio justo e adequado de acordo com o risco assumido, havendo até a possibilidade do segurado perder o direito à indenização, caso não preste informações verdadeiras, conforme artigo do CC (2002):

Art. 766. Se o segurado, por si ou por seu representante, fizer declarações inexatas ou omitir circunstâncias que possam influir na aceitação da proposta ou na taxa do prêmio, perderá o direito à garantia, além de ficar obrigado ao prêmio vencido.

Parágrafo único. Se a inexatidão ou omissão nas declarações não resultar de má-fé do segurado, o segurador terá direito a resolver o contrato, ou a cobrar, mesmo após o sinistro, a diferença do prêmio.

É justamente considerando o princípio da boa-fé que as companhias de seguros, tomando por base as informações e declarações do Segurado no questionário de avaliação de riscos, avaliam o risco proposto e definem a taxa do seguro a ser aplicada para cada Segurado e operação. Conforme orientação do guia emitido pela SUSEP (2006): 
Como é determinado o valor do prêmio de seguro? O valor do prêmio será fixado pela seguradora a partir das informações que lhe foram enviadas sobre o bem segurado (automóvel) e, em geral, sobre o segurado e o condutor (questionário de avaliação de risco). As seguradoras estão liberadas para fixar seus prêmios e a forma de pagamento (se o prêmio será à vista ou parcelado).

Assim, o segurado deve ser verdadeiro e responsável com relação às suas informações e atitudes, sob pena de liberar o segurador das obrigações contratuais. Dispõe o guia de orientação e defesa do segurado expedido pela Superintendência de Seguros Privados (2006):

A proposta de contratação ou de adesão deverá ser totalmente preenchida e assinada. Caso haja declaração pessoal de saúde, questionário de perfil ou de avaliação de risco, deve-se responder a todas as perguntas de forma correta e completa, pois caso haja alguma declaração falsa, isto poderá acarretar a negativa de pagamento da indenização.

No mais, eventual agravamento do risco deve ser devidamente comunicado à Seguradora, sob pena de perder o direito à indenização, se comprovada a má-fé, conforme estabelecido no artigo 769 do CC (2002) "O segurado é obrigado a comunicar ao segurador, logo que saiba, todo incidente suscetível de agravar consideravelmente o risco coberto, sob pena de perder o direito à garantia, se provar que silenciou de má-fé."

Citamos como exemplos de agravamento do risco, a troca de endereço para uma residência sem vaga de garagem, situação em que o veículo passará a noite inteira estacionado na rua.

No caso de o segurado intencionalmente omitir fato que agrave o risco ou fornecer informações em desacordo com a verdade, poderá ocorrer perda do direito à indenização, mesmo se o evento possuir cobertura na apólice contratada, conforme instruções da Agência Reguladora (SUSEP, s.d):

O que se entende por perda de direito?

Trata-se da ocorrência de um fato que provoca a perda do direito do segurado à indenização, ainda que, a princípio, o sinistro seja oriundo de um risco coberto, ficando, então, a seguradora isenta de qualquer obrigação decorrente do contrato.

RC: 104723

Disponível em: https://www.nucleodoconhecimento.com.br/lei/contrato-de-seguro 
Ocorre a perda de direito se:

- O sinistro ocorrer por culpa grave ou dolo do segurado ou beneficiário do seguro;

- A reclamação de indenização por sinistro for fraudulenta ou de má-fé;

- O segurado, corretor, beneficiários ou ainda seus representantes e prepostos fizerem declarações falsas ou, por qualquer meio, tentarem obter benefícios ilícitos do seguro;

- O segurado agravar intencionalmente o risco.

Além disso, se o segurado, seu representante, ou seu corretor de seguros fizer declarações inexatas ou omitir circunstâncias que possam influir na aceitação da proposta ou no valor do prêmio, ficará prejudicado o direito à indenização, além de estar o segurado obrigado ao pagamento do prêmio vencido.

Por fim, outra obrigação importante do segurado é a de apresentar toda a documentação solicitada pela Seguradora para análise em ocorrências de sinistro. Em caso de sinistro, é natural que a Cia de Seguros solicite uma série de documentos necessários para analisar a ocorrência, avaliar os danos, verificar as circunstâncias do evento, comprovar a propriedade do veículo, entre outros a depender de cada situação específica.

Diante deste quadro, cabe ao segurado a obrigação de apresentar toda documentação solicitada e em caso de impossibilidade esclarecer os motivos pelos quais não consegue enviar a documentação completa, para receber a indenização e garantir a agilidade na prestação do serviço.

\section{CONCLUSÃO}

Diante de todo o exposto, ficou claro que o contrato de seguro de automóvel possui diversas nuances e deve ser minuciosamente analisado pelo segurado antes de finalizar a contratação para que seja verificado se o contrato atende todas as suas exigências e necessidades.

Após aceitação do risco por parte da Seguradora, será emitida a apólice com todas as especificações das cláusulas e coberturas contratadas, além dos procedimentos

RC: 104723

Disponível em: https://www.nucleodoconhecimento.com.br/lei/contrato-de-seguro 
de abertura e liquidação de sinistro e todas as demais informações necessárias para compreensão do seguro firmado.

Pactuado o contrato de seguro, geram-se direitos e deveres a ambos os contratantes. Seguradora e segurado assumem obrigações e com seu cumprimento passam a ser titulares de direitos.

$\mathrm{O}$ artigo conseguiu atingir o objetivo geral proposto, pois esclareceu as principais características do contrato de seguro de automóvel, sobretudo, a questão norteadora que era informar sobre os principais direitos e deveres do segurado em um contrato de seguro. Extraindo a conclusão de que, como principais direitos do segurado, têm-se as obrigações da Seguradora de: oferecimento da assistência contratada; clareza nas especificações do contrato; aviso acerca de eventuais alterações contratuais; e cumprimento do prazo de liquidação do sinistro.

Já o segurado, para garantir a proteção do seu veículo deverá sempre estar em dia com as parcelas do prêmio pactuado. Além disso, o segurado tem o dever de: prestar informações corretas no momento da contratação do segurado; informar sobre agravamento de riscos e mudanças referentes ao contrato; enviar toda documentação solicitada pela Seguradora para análise do sinistro; e sempre agir com verdade, probidade e boa-fé.

\section{REFERÊNCIAS}

ASSOCIAÇÃO DOS OFICIAIS DE JUSTIÇA DO ESTADO DE SÃO PAULO. SEGURO DE VEíCULOS: Conheça os seus direitos. São Paulo: 2011. Disponível em https://aojesp.jusbrasil.com.br/noticias/2993546/seguro-de-veiculosconheca-os-seus-direitos. Acesso em 07/10/2021

\section{BISELLI, Giuliana. O contrato de seguro e suas principais características.} Jusbrasil, publicado em $2015 . \quad$ Disponível em: https://giulianabiselli.jusbrasil.com.br/artigos/179663397/o-contrato-de-seguro-esuas-principais-caracteristicas. Acesso em 07/10/2021. 
BRASIL. Lei no 10.406, de 10 de janeiro de 2002. Institui o Código Civil. Disponível em: http://www.planalto.gov.br/ccivil_03/leis/2002/l10406compilada.htm. Acesso em 07/10/2021.

BRASIL. Lei n $\mathbf{8 . 0 7 8}$, de 11 de setembro de 1990. Dispõe sobre a proteção do $\begin{array}{llll}\text { consumidor dé outras providências. Disponível } & \text { dá }\end{array}$ em: http://www.planalto.gov.br/ccivil_03/leis//8078compilado.htm. Acesso em 07/10/2021.

BRASIL. Superior Tribunal de Justiça. Súmula ํ 616 de 23/05/2018.

CUNHA, José Sabastião Fagundes. Contratos de seguro estabelecem relação de consumo. Consultor Jurídico, publicado em 31/03/2012. Disponível em: https://www.conjur.com.br/2012-mar-31/contratos-seguro-estabelecem-relacaoconsumo-sao-regidos-cdc. Acesso em 07/10/2021.

DAU, Gabriel. Direito do Consumidor na contratação de seguros. Rede Jornal Contábil, publicado em 06/11/2020. Disponível em: https://www.jornalcontabil.com.br/direito-do-consumidor-na-contratacao-de-seguros/. Acesso em 07/10/2021.

ELAINA, Jeniffer. Como funciona a cobertura para danos morais no seguro auto. Da Veiga \& Higuchi Corretora de Seguros, publicado em 2/09/2019. Disponível em: $\quad$ https://daveigaseguros.com.br/blog/direitos-do-consumidor-nos-seguros/. Acesso em 07/10/2021.

HENDLER, Alessandra Fernandes. Normas Legais Do Contrato De Seguro: CC ou CDC?, publicado em setembro de 2006. Disponível em: https://www.univates.br/media/graduacao/direito/NORMAS_LEGAIS_DO_CONTRAT O_DE_SEGURO.pdf. Acesso em 07/10/2021.

HIGUCHI, DA VEIGA \&. Direitos do consumidor nos seguros: veja os principais pontos!. Smartia Blog, publicado em 30/03/2021. Disponível em: 
https://www.smartia.com.br/blog/cobertura-para-danos-morais-no-seguro-auto/. Acesso em 07/10/2021.

LUYZE, Patrícia. Quais seus direitos ao contratar um seguro auto. JUS, publicado em 08/2020. Disponível em: https://jus.com.br/artigos/84924/quais-seusdireitos-ao-contratar-um-seguro-auto. Acesso em 07/10/2021.

MONTEIRO, Washington de Barros. Curso de Direito Civil. São Paulo: Editora Saraiva, 2009, v. 5.

ROCHA, Aparecido Mendes. Natureza jurídica do contrato de seguro. Legislação do corretor de seguros, publicado em 18/04/2014. Disponível em: https://www.legiscor.com.br/noticias/natureza-juridica-do-contrato-de-seguro. Acesso em 07/10/2021.

SUSEP - SUPERINTENDÊNCIA DE SEGUROS PRIVADOS. Guia de Orientação e Defesa do Segurado, 2. ed. Rio de Janeiro: SUSEP, 2006. Disponível em https://www2.susep.gov.br/download/cartilha/cartilha_susep2e.pdf. Acesso em 07/10/2021.

\section{SUSEP - SUPERINTENDÊNCIA DE SEGUROS PRIVADOS. Perguntas mais} frequentes sobre seguros. Disponível em http://www.susep.gov.br/setoressusep/seger/coate/perguntas-mais-frequentes-sobre-seguros-

1\#: :text=3\%2D\%200\%20que\%20\%C3\%A9\%20pr\%C3\%AAmio,das\%20principais \%20obriga\%C3\%A7\%C3\%B5es\%20do\%20segurado. Acesso em 11/12/2021.

\section{APÊNDICE - REFERÊNCIA NOTA DE RODAPÉ}

2. BRASIL. Lei o 8.078 , de 11 de setembro de 1990. Dispõe sobre a proteção do consumidor e dá outras providências. Disponível em: http://www.planalto.gov.br/ccivil_03/leis//8078compilado.htm. Art. 3․ Fornecedor é toda pessoa física ou jurídica, pública ou privada, nacional ou estrangeira, bem como os entes despersonalizados, que desenvolvem atividade de produção, montagem, criação, construção, transformação, importação, exportação, distribuição 
ou comercialização de produtos ou prestação de serviços. § 2. Serviço é qualquer atividade fornecida no mercado de consumo, mediante remuneração, inclusive as de natureza bancária, financeira, de crédito e securitária, salvo as decorrentes das relações de caráter trabalhista.

3. Art. 759. A emissão da apólice deverá ser precedida de proposta escrita com a declaração dos elementos essenciais do interesse a ser garantido e do risco.

Enviado: Outubro, 2021.

Aprovado: Janeiro, 2022. 